\title{
Pemetaan Eksterior Gedung 3 Dimensi (3D) Menggunakan Electronic Total Station (ETS)
}

\author{
RINALDY, RAHMAT TAUFIK HIDAYAT
}

\author{
Jurusan Teknik Geodesi \\ FTSP - Institut Teknologi Nasional, Bandung \\ Email: rinaldy583@gmail.com
}

\begin{abstract}
ABSTRAK
Saat ini masih banyak orang yang melakukan pemetaan 2D, tetapi seiring berkembangnya teknologi pemetaan secara 3D mulai dikembangkan. Pada studi ini kegiatan pemetaan dilakukan dengan metode terestris dengan melakukan pengukuran sudut dan jarak untuk mendapatkan posisi berupa $x, y, z$ dan data keruangan berupa panjang, lebar, dan tinggi. Pada studi ini, pemetaan 3D lebih dikembangkan dengan melakukan pengukuran metode terestris dengan menggunakan alat Electronic Total Station (ETS). Namun, tidak semua objek dapat diukur menggunakan alat ETS, dikarenakan wilayah pengukuran terletak pada daerah yang padat dengan bangunan gedung sehingga membatasi ruang gerak pengukuran. Dari hasil studi ini dapat disimpulkan sebagai berikut: (1) pengambilan data detail situasi tidak hanya mengambil batas-batas atap dari setiap objek, melainkan setiap detail objekobjek seperti pilar, pintu, jendela, tangga, atap, rangka atap, ventilasi; (2) titik-titik detail situasi yang diukur adalah sudut-sudut dari setiap detail objek di mana titik-titik detail situasi yang diukur menggunakan metode seperti metode polar dan metode trigonometri; (3) data detail situasi yang diolah adalah posisi vertikal (z) untuk mendapatkan beda tinggi. Beda tinggi tersebut digunakan untuk penggambaran objek 3D; (4) peta 3D yang dihasilkan sesuai dengan posisi, ukuran, dan bentuknya.
\end{abstract}

Kata kunci : Pemetaan 3D, ETS, Level of Detail, Metode Trigonometri

\begin{abstract}
Currently there are many people who do 2D mapping, but as the development of a $3 D$ mapping technology was developed. In this study mapping exercise carried out by terrestrial methods by measuring the angle and distance to get the position in the form of $x, y, z$ and spatial data such as length, width and height. In this study, the 3D mapping is developed by measuring the terrestrial method by using the Electronic Total Station (ETS). However, not all objects can be measured using the ETS, because the measuring region lies in a dense area with buildings that limits the space of measurement. The results of this study can be summarized as follows: (1) retrieval of detailed data of the situation not only take the roof boundaries of each object, but every detail of objects such as pillars, doors, windows, stairs, roof, roof truss, ventilation; (2) the detail points of the situation measured are the angles of each detail of the object in which the detail points of the situation are measured using methods such as polar methods and trigonometric methods; (3) the processed data of detail situation is vertical position ( $z$ ) to obtain a height difference, which used for 3D object depiction; (4) the resulting 3D map matches the position, size, and shape.
\end{abstract}

Keywords: 3D Mapping, ETS, Level of Detail, Trigonometry Method 


\section{PENDAHULUAN}

Peta adalah "suatu representasi atau gambaran unsur-unsur sebagian atau keseluruhan obyek permukaan bumi yang digambarkan pada suatu bidang datar dengan menggunakan skala dan sistem proyeksi tertentu" (Wongsotjitro, 1980). Peta yang merupakan hasil kegiatan pemetaan dengan menentukan posisi $\mathrm{x}$ dan y baik dilakukan dengan pengukuran langsung terestris (pengamatan terhadap obyek yang terletak di permukaan bumi secara pengukuran langsung) ataupun ekstra-terestris (pengamatan terhadap obyek secara tidak langsung atau menggunakan instrumen (alat) tertentu, seperti satelit dan pesawat) adalah peta yang direpresentasikan secara 2 Dimensi (2D) dalam bentuk data garis (Purworahardjo, 1986).

Saat ini masih banyak orang yang melakukan pemetaan 2D, tetapi seiring berkembangnya teknologi pemetaan secara 3D mulai dikembangkan. Pada studi ini kegiatan pemetaan dilakukan dengan metode terestris dengan melakukan pengukuran sudut dan jarak untuk mendapatkan posisi berupa $\mathrm{x}, \mathrm{y}, \mathrm{z}$ dan data keruangan berupa panjang, lebar dan tinggi. Pemetaan 3D pada kampus Institut Teknologi Nasional (Itenas) sudah pernah dilaksanakan, namun pada studi sebelumnya metode yang digunakan adalah menggabungkan data foto hasil pemotretan kamera dan pengukuran tinggi dari hasil pengukuran terestris yang kemudian diolah menjadi peta 3D. Pada studi ini, pemetaan 3D lebih dikembangkan dengan melakukan pengukuran metode terestris dengan menggunakan alat Electronic Total Station (ETS). Tetapi tidak memungkinkan semua obyek dapat diukur menggunakan alat ETS, dikarenakan wilayah pengukuran terletak pada daerah yang padat dengan bangunan gedung sehingga membatasi ruang gerak pengukuran, maka dilakukan pengukuran relatif (pengukuran terhadap titik yang telah diukur) dengan menggunakan pita ukur.

Pengukuran yang dilakukan ditujukan untuk mendapatkan data berupa koordinat ( $x, y$ dan $z$ ) yang kemudian dibangun menjadi gambar 3D (Clemens dkk., 1994). Pengukuran yang dilakukan ini mengacu pada Level of Detail (LoD) City Geography Markup Language (CityGML) (Biljecki, 2013). Berdasarkan LoD tersebut, tingkatan pengukuran ini adalah sampai dengan LoD2, hal ini dilakukan untuk efisiensi pengukuran khususnya pada bagian eksterior. Hasil akhir dari studi ini adalah peta 3D yang divisualisasikan menggunakan software Autocad pada laptop atau personal computer.

\section{METODOLOGI PENELITIAN}

Langkah awal dari studi adalah dengan melakukan studi literatur, persiapan administratif, dan persiapan pengukuran. Pelaksanaan pengukuran dilakukan berdasarkan pengikatan pada kerangka dasar pemetaan (KDP) yang terdiri atas kerangka dasar horizontal dan kerangka dasar vertikal. Kemudian dilanjutkan dengan pengolahan data kerangka dasar pemetaan menggunakan software Ms. Excel. Setelah didapatkan koordinat definitif maka dilakukan pengukuran detail situasi dan melakukan pengolahan data detail situasi menggunakan software Ms. Excel dan software Autocad Land Desktop seperti yang dilakukan oleh Sastra dan Suparno (2014). Data detail situasi topografi yang telah diolah disajikan menggunakan software Autocad, dan dilanjutkan pada pembahasan dan kesimpulan. Proses tersebut akan dijabarkan kembali berdasarkan diagram alir pada gambar 1. 

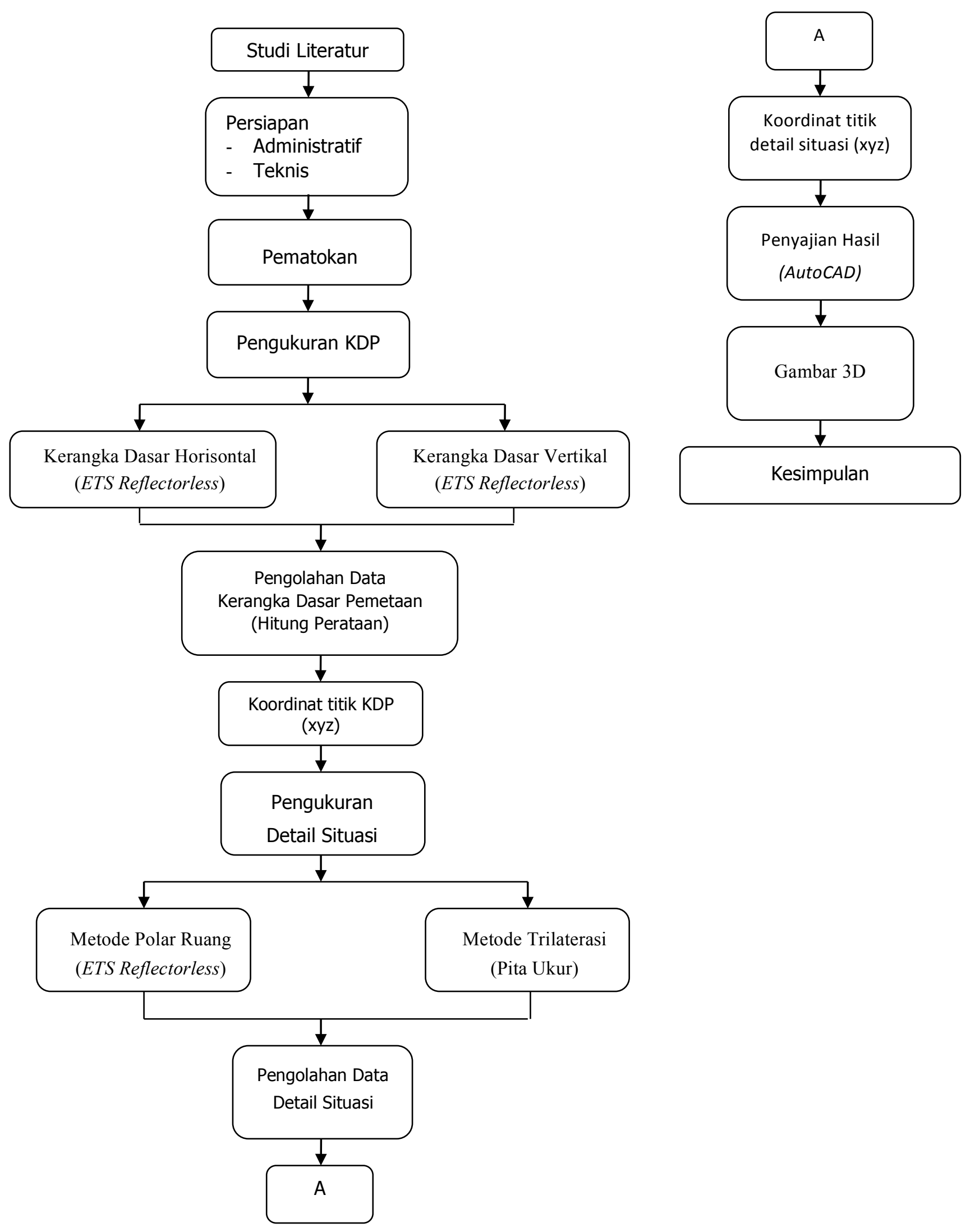

Gambar 1. Diagram Alir Metodologi Penelitian 


\section{HASIL DAN PEMBAHASAN}

\subsection{Hasil}

Hasil dari studi yang dilakukan adalah peta 3D divisualisasikan dengan menggunakan software Autocad. Peta yang divisualisasikan berbentuk softcopy. Peta tersebut dihasilkan dari pengukuran menggunakan metode-metode yang mendukung sehingga dapat menghasilkan suatu peta 3D. Metode yang digunakan adalah metode Poligon yang digunakan untuk pengambilan titik kerangka dasar, metode Polar, metode Trigonometri dan metode Trilaterasi digunakan untuk pengambilan detail situasi. Kesalahan penutup absis (KPA) adalah sebesar $-0.012 \mathrm{~m}$, kesalahan penutup ordinat (KPO) $-0.052 \mathrm{~m}$, kesalahan penutup beda tinggi (KPB) adalah sebesar $0.019 \mathrm{~m}$. Nilai koordinat kerangka dasar seperti terlihat pada tabel 1. Hasil gambar 3D dapat dilihat pada gambar 2, 3 dan 4.

Tabel 1. Nilai Koordinat Kerangka Dasar

\begin{tabular}{|c|c|c|c|}
\hline No. Titik & $X(\mathrm{~m})$ & $\mathrm{Y}(\mathrm{m})$ & $\mathrm{Z}(\mathrm{m})$ \\
\hline ITN13 & 791274.012 & 9236904.197 & 749.270 \\
\hline ITN46 & 791263.814 & 9236924.268 & 749.396 \\
\hline P1 & 791237.704 & 9236940.127 & 750.236 \\
\hline P2 & 791238.102 & 9236946.674 & 750.107 \\
\hline P3 & 791251.111 & 9236949.235 & 749.736 \\
\hline P4 & 791289.859 & 9236939.530 & 749.508 \\
\hline P5 & 791294.268 & 9236941.185 & 749.498 \\
\hline P6 & 791318.494 & 9236934.663 & 749.394 \\
\hline P7 & 791338.228 & 9236929.157 & 748.815 \\
\hline P8 & 791351.733 & 9236907.094 & 749.012 \\
\hline P9 & 791373.800 & 9236893.973 & 748.415 \\
\hline P10 & 791365.677 & 9236869.563 & 748.364 \\
\hline P11 & 791340.024 & 9236878.226 & 748.450 \\
\hline P12 & 791307.610 & 9236895.919 & 749.033 \\
\hline
\end{tabular}

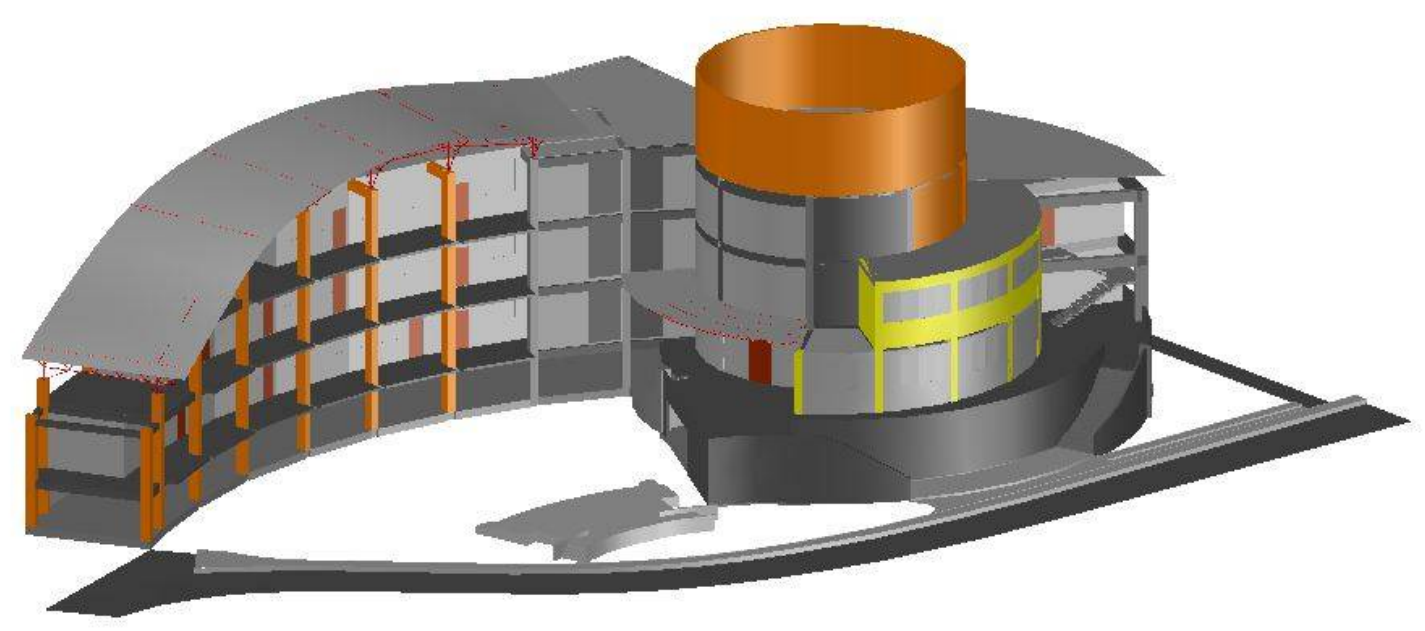

Gambar 2. Obyek 3D Gedung Student Centre

Reka Geomatika - 37 


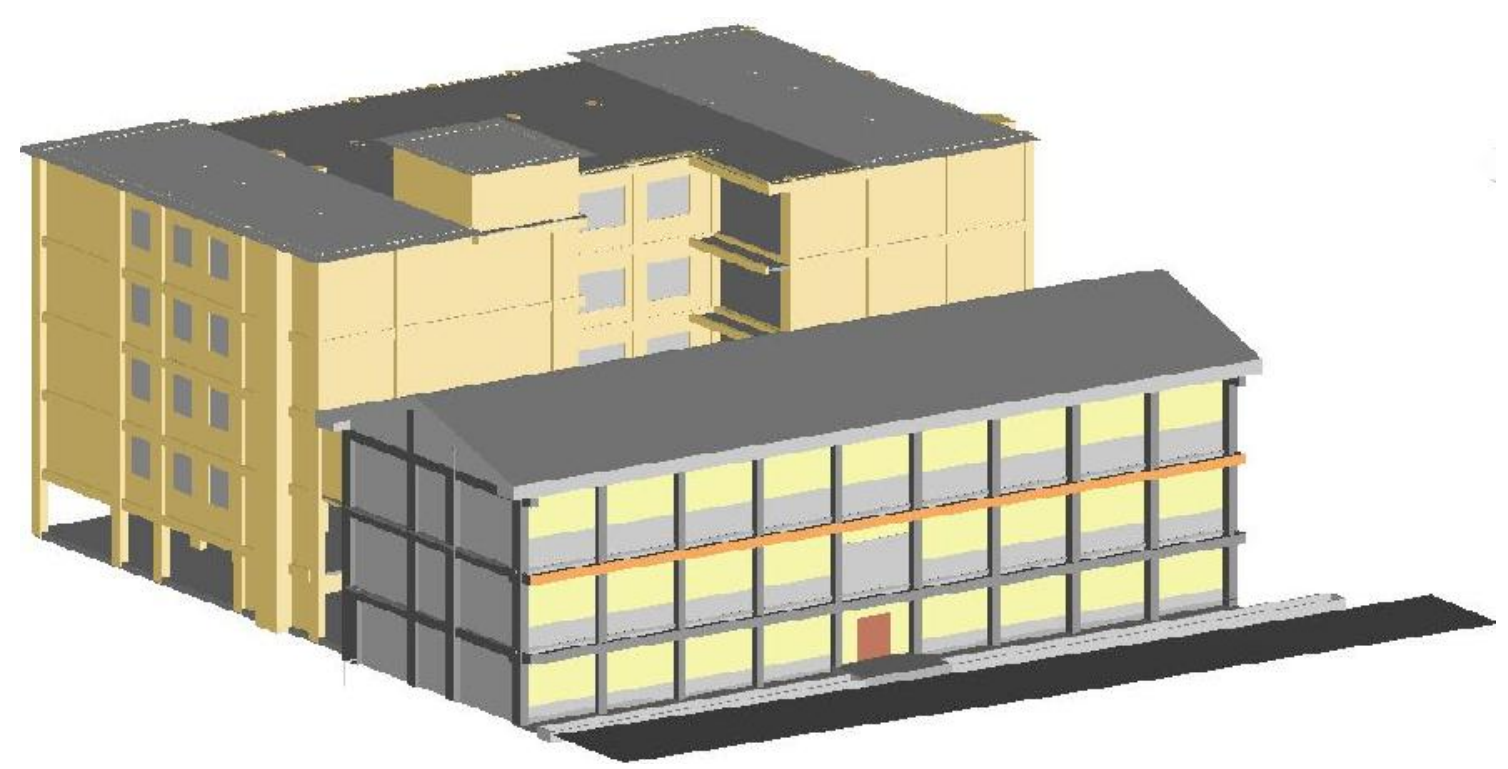

Gambar 3. Obyek 3D Gedung Desain Interior

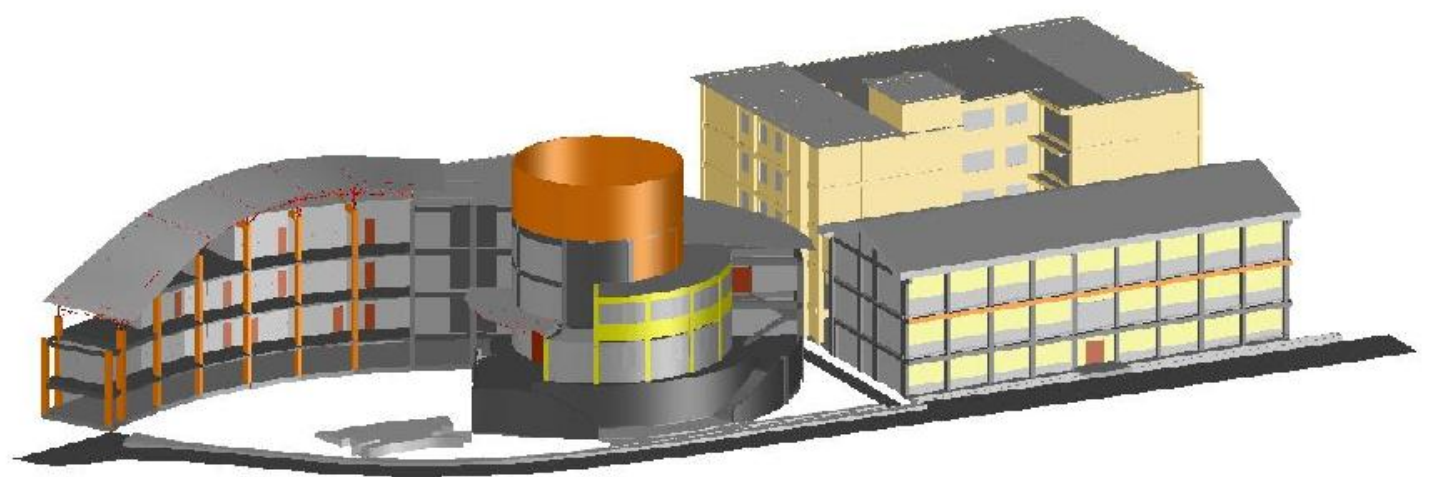

Gambar 4. Obyek 3D Ketiga Gedung

\subsection{Pembahasan}

Pemetaan yang dilakukan sebelum berkembangnya pemetaan 3D, merupakan pemetaan dengan melakukan pengukuran horisontal dan vertikal dengan menghasilkan peta topografi. Seiring berkembangnya zaman, pemetaan tidak hanya melakukan pengukuran titik-titik detail yang diproyeksikan terhadap bidang datar dan hanya mewakili dari obyek bangunan, sebagai contoh batas atap bangunan. Tetapi dalam pemetaan 3D, pengukuran titik-titik detail situasi dilakukan dengan mengukur dari setiap detail obyek bangunan seperti pilar, pintu, jendela, atap, rangka atap, tangga, tembok. Semua bagian-bagian bangunan digambarkan dalam bentuk 3D. Jadi pemetaan 3D tidak hanya menggambarkan permukaan tanah dan bidang-bidang bangunan yang ada di atasnya, tetapi pemetaan 3D ini menggambarkan permukaan tanah dan obyek-obyek yang ada di permukaan tanah dengan cara 3D.

Pengambilan data detail situasi 3D detail yang diambil tidak hanya setiap batas atap bangunan, melainkan semua detail dari obyek bangunan. Seperti pintu, jendela, atap, pilarpilar, ventilasi, dan yang lain harus diambil disetiap sudut-sudut dari obyek tersebut seperti terlihat pada gambar $5,6,7,8,9,10$. 
Pemetaan Eksterior Gedung 3 Dimensi (3D) Menggunakan Electronic Total Station (ETS)

Keterangan gambar 5 .

0 : Pengambilan titik-titik detail pintu

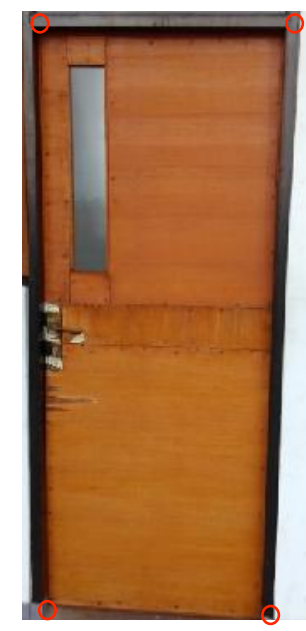

\section{Gambar 5. Obyek Pintu}

Keterangan gambar 6 .

0 : Pengambilan titik-titik detail jendela

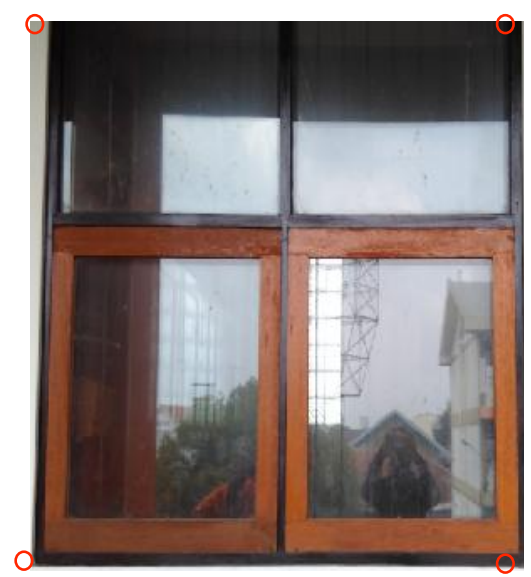

Gambar 6. Obyek Jendela

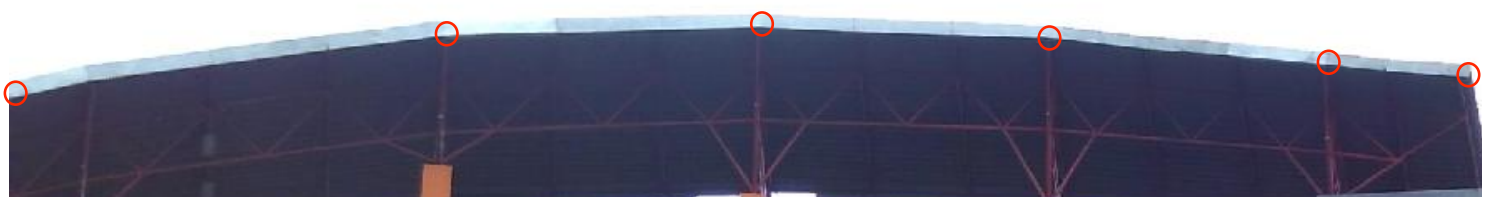

Keterangan gambar 7.

0 : Pengambilan titik-titik detail atap

Gambar 7. Obyek Atap 
Rinaldy dan Rahmat Taufik Hidayat

Keterangan gambar 8.

0 : Pengambilan titik-titik detail pilar

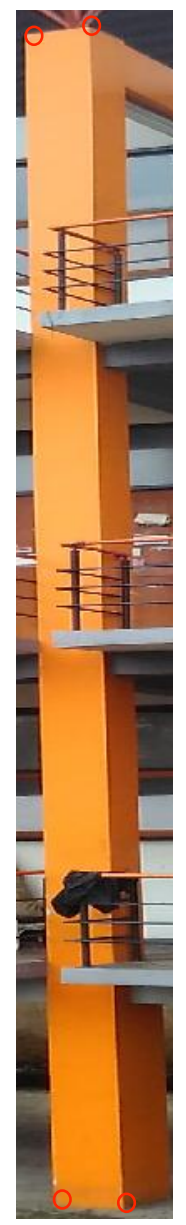

Gambar 8. Obyek Pilar

Keterangan gambar 9.

0 : Pengambilan titik-titik detail ventilasi

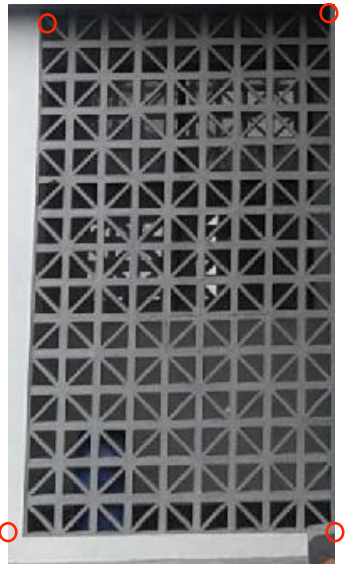

Gambar 9. Obyek Ventilasi 
Keterangan gambar 10.

0 : Pengambilan titiktitik detail rangka atap

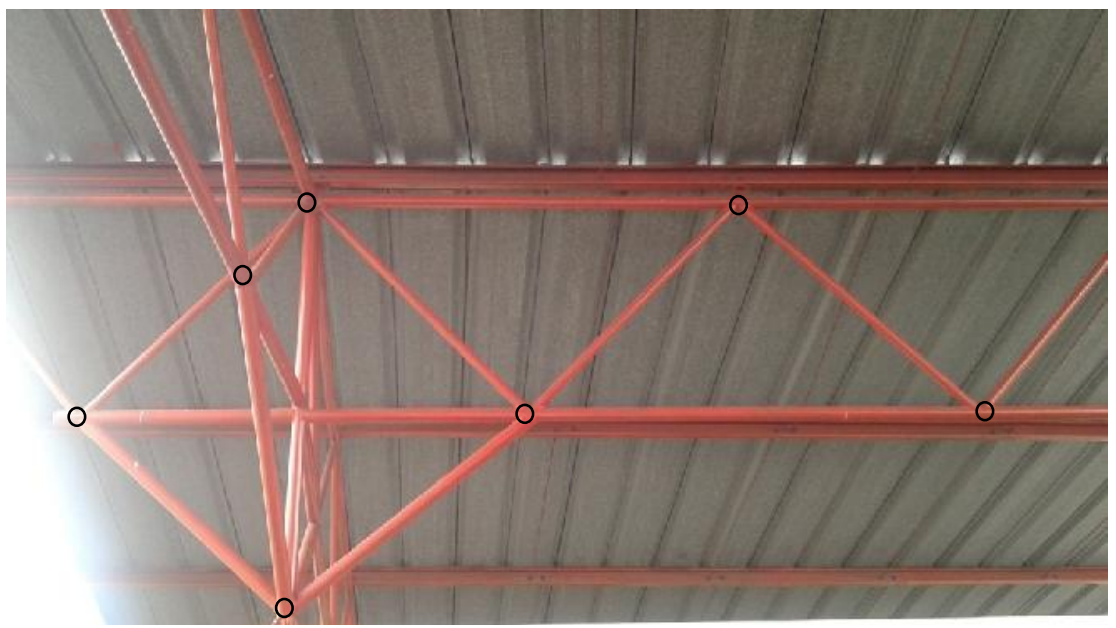

Gambar 10. Obyek Rangka Atap

Untuk penggambaran gambar 3D, diperlukan beda tinggi dari setiap detail obyek, sehingga posisi vertikal $(\mathrm{z})$ perlu dilakukan pengolahan untuk mendapatkan beda tinggi dari setiap detail obyek. Beda tinggi yang dihasilkan digunakan pada saat penggambaran obyek 3D untuk memudahkan penggambaran. Pada saat penggambaran 3D menggunakan AutoCAD 3D, data bidang 2D belum memiliki tinggi yang sebenarnya atau tingginya sama dengan 0 . Maka dari itu dilakukan pemindahan satu persatu bidang 2D ketinggi yang sebenarnya dari setiap detail obyek. Setelah itu digambar 3D dengan menambahkan beda tinggi dari setiap obyek.

\section{KESIMPULAN}

Dari studi yang telah dilakukan dapat diambil kesimpulan sebagai berikut: (1) pengambilan data detail situasi tidak hanya mengambil batas-batas atap dari setiap objek, melainkan setiap detail objek-objek seperti pilar, pintu, jendela, tangga, atap, rangka atap, ventilasi; (2) titik-titik detail situasi yang diukur adalah sudut-sudut dari setiap detail objek di mana titik-titik detail situasi yang diukur menggunakan metode seperti metode polar dan metode trigonometri; (3) data detail situasi yang diolah adalah posisi vertikal (z) untuk mendapatkan beda tinggi. Beda tinggi tersebut digunakan untuk penggambaran objek 3D; (4) peta 3D yang dihasilkan sesuai dengan posisi, ukuran, dan bentuknya.

\section{DAFTAR RUJUKAN}

Biljecki, F.. (2013). The Concept Of Level Of Detail In 3D City Models. Belanda. TU Delft.

Clemens, S., O'Daffer, P., dan Cooney, T. (1994). Geometry. Canada: Publishing Addison/Wesley.

Purworahardjo, U. (1986). Ilmu Ukur Tanah Seri C - Pengukuran Topografi. Bandung: Teknik Geodesi ITB.

Sastra, M. dan Suparno. (2014). Desain Rancang Bangun 3D dan Interior dengan Autocad. Yogyakarta. ANDI Offset.

Wongsotjitro, S. (1980). IImu Ukur Tanah. Yogyakarta: Kanisius. 